\title{
WHY DO MINORITY MEN EARN LESS? A STUDY OF WAGE DIFFERENTIALS AMONG THE HIGHLY EDUCATED
}

\author{
Dan Black, Amelia Haviland, Seth Sanders, and Lowell Taylor*
}

\begin{abstract}
We estimate wage gaps using nonparametric matching methods and detailed measures of field of study for university graduates. We find a modest portion of the wage gap is the consequence of measurement error in the Census education measure. For Hispanic and Asian men, the remaining gap is attributable to premarket factors-primarily differences in formal education and English language proficiency. For black men, only about one-quarter of the wage gap is explained by these same factors. For a subsample of black men born outside the South to parents with some college education, these factors do account for the entire wage gap.
\end{abstract}

\section{Introduction}

$\mathrm{M}$ EN in several minority groups in the United States have wages that are substantially lower than those of the benchmark majority group-non-Hispanic white men. Several generations of labor economists have sought to understand the forces that drive these disparities. This research program is potentially important for the purpose of determining whether minority wage gaps are likely to be narrowed more effectively by increasing enforcement of antidiscrimination laws or by implementing policies that reduce inequity in educational opportunity.

Existing work shows large racial and ethnic differences in premarket factors, especially formal schooling, and suggests that these differences play a key role in shaping wage differences. One example is Trejo (1997), who finds that third- and higher-generation Mexican American men earn $21 \%$ less than non-Hispanic white men. Approximately three-quarters of the earnings gap is found to be attributable to the Mexican Americans' relative youth and to differences in English language proficiency and years of schooling. A second example is Neal and Johnson (1996), who find that black men earn $24 \%$ less than do non-Hispanic white men. Differences in schooling account for only about one-fifth of this gap. When the authors condition on performance on a basic verbal and math skills test, the Armed Forces Qualification Test (AFQT), though, the differential between wages of blacks and whites declines to approximately onethird of its unadjusted level. ${ }^{1}$

Trejo's (1997) study is a nice example of the traditional approach to studying race/ethnicity wage gaps-traditional in the sense that the explanatory variables in the study are conventional "objective" measures of human capital, such as years of schooling and language ability. Neal and John-

Received for publication October 17, 2003. Revision accepted for publication April 19, 2005.

*Syracuse University, Carnegie Mellon University, University of Maryland, and Carnegie Mellon University, respectively.

We gratefully acknowledge financial support from the NICHD. Stephen Feinberg and Mel Stephens provided helpful comments, as did seminar participants at Houston, Maryland, Purdue, Queens, Rice, SMU, UCLA, Carnegie Mellon, and UCSB.

${ }^{1}$ Many other examples along these lines are found in the Altonji and Blank's (1999) important review of wage disparities. son (1996) depart from the traditional approach in including a measure of academic achievement, performance on the AFQT, in their wage regressions (see also O'Neil, 1990). A reasonable motivation for use of the AFQT score as a measure of human capital stems from a problem that is lurking in the background of the wage-gap literature: the primary human capital variable typically used in wage regressions-years of schooling - is a very crude measure. It fails to allow, for example, for differences in quality or intensity of education. Thus, owing to large disparities in U.S. primary and secondary education, a black with 12 years of education will often have a lower level of relevant human capital than a corresponding white. Neal and Johnson argue that the AFQT achievement score is a better summary measure of premarket human capital than is years of schooling and is thus more helpful in empirical analyses that examine the role of premarket factors on the race wage gap.

The use of the AFQT as a proxy for human capital is controversial. The literature discusses at least three related concerns. The first issue is fundamental: what precisely is being measured by the AFQT? Although there are good reasons to doubt claims by Herrnstein and Murray (1994) that the score is best thought of as a measure of native intelligence, neither is measured performance on a short achievement test an entirely satisfactory indicator of an individual's investment in human capital. ${ }^{2}$ Thus, though the test may be helpful in measuring such valued traits as vocabulary retention and capacity for abstract reasoning, it surely misses other valued traits that one might learn in school, such as specific domain knowledge, computer skills, persistence in completing tasks, or the ability to work with others. Second, as discussed by Rodgers and Spriggs (1996), if the AFQT suffers from racial bias or if differences in test-taking ability (or inclination to perform well on tests) are correlated with race, the test score would disproportionately underestimate the true level of human capital for blacks. The resulting empirical analysis would tend to overstate the role of premarket factors in accounting for the black-white wage gap. ${ }^{3}$ Third, econometric issues arise when one thinks of the AFQT as an imperfect measure of human capital. ${ }^{4}$

\footnotetext{
${ }^{2}$ For example, performance on the AFQT is affected by schooling. Altonji and Blank (1999) provide a discussion and references to other relevant literature.

${ }^{3}$ Neal and Johnson (1996) provide a thoughtful discussion of this issue; race bias in testing is a difficult issue to resolve.

${ }^{4}$ Bollinger (2003) treats the issue as an errors-in-variables problem, suggesting that Neal and Johnson (1996) actually underestimate the importance of human capital in explaining the black-white wage difference among men.
} 
In short, although we would surely prefer a measure of human capital that is more detailed than the years-ofschooling variable usually used in wage regressions (for example, a measure that incorporates differences in school curriculum, teacher expertise, or level of individual attention), we might also prefer that such a measure not rely in a serious way on individual test-taking ability. Such a measure is of course not readily available.

Against this backdrop we present here a new empirical examination of minority wage gaps that focuses on collegeeducated men. Like Neal and Johnson (1996), we are interested in the role of premarket factors in shaping labor market outcomes. Thus, in our analyses we do not condition on experience or occupation. Our concern is that discrimination may be responsible for some of the racial differences in occupation (for example, if employers disproportionately assign minority men to lower-ranking occupations while paying all men equally within the employer-labeled roles) or in experience (for example, if minority workers are more likely than other men to be laid off). Unlike Neal and Johnson (1996), however, we adopt the traditional approach of relying on nontest measures of premarket human capital for the data we use for our analysis, from the National Survey of College Graduates (NSCG), have no test-based measures of achievement. We do have, though, data on degree level (bachelor's, master's, professional, $\mathrm{PhD}$ ) and exceptionally detailed data on the field associated with the highest degree. To the extent that the cumulative educational disadvantage experienced by many minority youth in the United States is manifest in an inability and/or disinclination to tackle difficult, but subsequently lucrative, courses of study in college, our detailed data are likely to be more helpful in taking account of relevant heterogeneity in schooling opportunity than are data that simply provide years of schooling (or highest degree).$^{5}$

Beyond the availability of suitable data, two additional factors motivate our focus on the college-educated. First, approximately 9 of 10 young Americans now complete at least a high school education, so much of the variation in completed education is at the college level. Because years of

\footnotetext{
${ }^{5}$ Of course, some of the observed racial/ethnic differences in human capital we observe may themselves be the consequence of discrimination. This can appear at the college level (for example, if minority college students are steered away from lucrative majors) or at the elementary and secondary level (for example, if minority students are discouraged from taking honors courses, or if fewer resources are made available to schools with large numbers of minority students). Such differences are said to be premarket in our analysis. Our use of detailed college-level educational outcomes parallels Brown and Corcoran's (1997) analysis of male-female wage differentials. The authors use the National Longitudinal Survey Class of 1972 and the third wave of the 1984 Panel of the Survey of Income and Program Participation to examine the effect of differences in the type of schooling acquired on gender differences in wages. By comparison with our data set, these data provide a small number of observations of respondents with a college education-far too few to study race/ethnicity differentials. Also, the NSCG data have the advantage of providing greater detail on college programs. There are 14 and 19 majors, respectively, in Brown and Corcoran's NLS and PSID data sets, but up to 144 different ones in the NSCG.
}

completed education are generally rising, we can expect the highly educated to become an increasingly important part of any explanation of minority wage disparities. Second, there is independent interest in the role of discrimination at the top end of the labor market. ${ }^{6}$ Evidence on this issue is most likely to appear in a study that focuses on well-educated individuals.

Because our sample is quite large, we are able to examine wages of three distinct minority groups: blacks, Hispanics, and Asians. As we show below, wages of men in each of these groups are lower than those of non-Hispanic white men. Because each of these minority groups has faced a history of discrimination and disadvantage, it is reasonable to look for empirical evidence of the wage disparity owing to such discrimination.

Black Americans face discrimination in the labor market that is surely less pervasive and overt than it was prior to the Civil Rights Act of 1964. Nonetheless, bigotry and racial misunderstanding persist. In addition, a disproportionate number of blacks have had poor access to education. Blacks on average have lower levels of completed education than whites, and there are also large differences in the quality of education available to blacks and whites. As we have emphasized, our analysis allows us to capture one systematic portion of this heterogeneity-heterogeneity that takes the form of racial differences in highest degree and major or field of study. We also make some headway in dealing with the large black-white socioeconomic disparities by using data on region of birth and parent's educational attainment, which may serve as proxies for differences in unobservable premarket factors that are likely to affect educational opportunity and human capital quality.

Like black men, Hispanic and Asian men earn less than non-Hispanic white men, though the root causes of these differentials seem likely to differ, to some extent, from those driving the black-white gap. Unlike African Americans, Hispanic and Asian Americans are largely immigrants or children of immigrants. In the sample we study, the majority of both Hispanic and Asian college-educated men speak a language other than English at home. For these ethnic groups, then, the role of English language ability, and assimilation more generally, is likely to be important. Beyond this, Hispanic men, like black men, generally have low levels of premarket human capital, whereas Asian men typically have quite high levels.

We can briefly summarize our key findings. Census data, attached to the NSCG records, indicate that collegeeducated men in each minority group earn less than nonHispanic white men: unadjusted wage gaps are approximately $19 \%$ for both blacks and Hispanics and $10 \%$ for Asians. A modest fraction of these wage gaps appears to be the consequence of measurement error in the recording of education in the Census. For Hispanics and Asians, the

\footnotetext{
${ }^{6}$ See, for example, Duleep and Sanders's (1992) exploration of this issue for Asian-American men.
} 
entire remaining gap is found to be attributable to premarket factors-differences in age structure, in formal education (in specific majors and degrees), and in English language proficiency (as measured by language spoken at home). For blacks in general, only about one-quarter of the wage gap is attributable to observed educational and age differences. Approximately three-quarters of the unadjusted gap, however, is explained when we restrict attention to individuals whose parents have some college education, and the entire gap is explained when we further restrict our focus to blacks who were not born in the South.

\section{The Data}

We use the 1993 National Survey of College Graduates (NSCG) to examine the degrees and disciplinary majors of college-educated men. The NSCG stems from an initiative of the National Science Foundation (NSF) that compiled information on scientists and engineers in the United States. The NSF and the Bureau of the Census conducted a survey based on the 1990 Decennial Census Long Form sampling frame, with the sample limited to those who had at least a baccalaureate degree and were 72 or younger as of April 1, 1990. The Census Bureau drew a stratified sample of 214,643 respondents, first contacting individuals with a mail survey, then, if necessary, with a telephone interview or in-person interview. In the collection of these data, a great deal of attention was paid to the accuracy of the education responses, and detailed information was gathered about the majors of the respondents for up to three degrees.

From the original selected sample, a few had emigrated from the United States $(2,132)$, had died $(2,407)$, were institutionalized (159), or were over 75 years old (211) and were hence of out of the survey's scope. Another 46,487 declined to participate. ${ }^{7}$ Surprisingly, 14,319 respondents reported having no four-year college degree despite reporting (or being allocated to) a four-year degree on the 1990 Census. ${ }^{8}$ These individuals are excluded from some, though not all, of our analyses. Once the out-of-scope groups are excluded, we have a (weighted) response rate of $80 \%$ or a sample of 148,928 respondents. In this paper we examine men only (which reduces the number of observations by 60,899), and because of the small sample size we choose to omit Native American men from the analysis (which reduces the sample by 682), giving 87,347 white, black, Hispanic, and Asian respondents.

\footnotetext{
${ }^{7}$ Respondents were considered refusals unless they provided information about their last degree and field of study.

${ }^{8}$ The small number of individuals who were "too old" apparently gave incorrect responses to the age question in the 1990 Census. Of those who reported not having a BA in the NSCG, $25 \%$ had their educational level imputed in the Census. Additional research by the NSF suggests that up to $20 \%$ of those who report not having a BA may actually have a BA, but denied having the degree as a mechanism for declining to be in the survey. Even allowing for these groups, there is a high level of measurement error in education in the 1990 Census (and, by extension, in other similar surveys, such as the CPS), which poses an interesting problem. See Black, Sanders, and Taylor (2003) for a discussion.
}

Because the sampling frame of the NSCG is the 1990 Census, anyone not having a degree by 1990 would not be included in the sample. As a result, we restrict the sample to those at least 25 years of age (in 1990) to ensure that most individuals would have had the opportunity to complete their undergraduate education. Similarly, we wish to avoid complications that might arise with differential retirement ages, so we restrict the sample to workers 60 years old and under. These age restrictions reduce the number of observations by 12,200 . The data include questions on sex, race, ethnicity, income from wages, and hours and weeks worked in the previous year. We exclude those who had imputed gender, race, age, or ethnicity (reducing the number of observations by 1,852$)$, who had imputed or zero wage incomes (reducing the number by 8,696), or who had imputed usual hours worked last year or weeks worked last year (reducing the number by 5,813). Workers who reported self-employment income in addition to wage income were not included, because there is no way of determining whether the hours and weeks worked refer only to the wage-earning job or to the self-employment job also, which would bias the calculated hourly wage (this reduces the number of observations by 6,681). The effects of exclusions based on missing or biased wage data are discussed in the results section. Another 100 respondents reported no major for their highest degree, and we dropped these respondents from most of our analyses. These exclusions leave us with a sample of 52,005 respondents.

For some of our analysis, we matched the NSCG data with original Census long-form data. The match was performed using 48 variables from the 1990 Census that were appended to each respondent's NSCG survey results. We were able to establish a unique match for all men for whom we have wage information. For these individuals we have detailed data on education from the NSCG, including identification of more than 140 different majors, as well as data from the Census, which includes information on location. We use these data to check for robustness of our reported results, which do not take account of differences in location.

\section{Wage Differentials: Decomposition Methods}

Our aim is to decompose minority wage gaps for highly educated men using premarket explanatory variables that affect wages and whose distributions differ between the demographic groups. In this section, we discuss our decision to use a nonparametric matching model in forming decompositions, and describe the procedure we use to calculate standard errors for our estimates.

\section{A. Nonparametric Decomposition}

Let the total wage gap for the demographic group $G_{j}$ be defined by the difference in conditional expected values,

$\Gamma\left(G_{j}\right)=E\left(y \mid G_{j}\right)-E(y \mid W)$, 
where $y$ is the natural logarithm of wages, $W$ indicates that respondents are non-Hispanic white males, and $G_{j}$ indicates that respondents are a member of the minority group $j$ (black, Hispanic, or Asian). Of course, in addition to minority status, other premarket characteristics affect wages and have distributions that differ between the groups. In attempting to isolate a possible effect of market discrimination, we would like to control for these premarket characteristics and separate the total wage gap into two components: an amount associated with differences in premarket attributes, and the amount remaining.

Matching provides an intuitively appealing method for estimating the missing counterfactuals: the wage a minority individual would earn if he were treated as a member of the benchmark majority group. To estimate the missing counterfactual for a 32-year-old Asian man with a master's degree in business administration, we use the mean of the wages of non-Hispanic white men of the same age with the same highest degree in the same field. ${ }^{9}$ Having estimated such counterfactuals for each member of the minority group, the mean gap (conditional on age and education) can be estimated by averaging over the gaps for individuals in the minority group. In the program evaluation literature such an estimator is said to estimate the effect of "treatment on the treated"; in this case "treatment" is minority group membership. The interpretation of the estimate is the average amount less (or more) that members of the minority group earn due to their minority status (or other relevant nonobservables that differ by minority status), given the age and education distribution for that minority group.

In our application, the covariates we use in decomposing the wage gaps - such as age (in years), highest degree, and major associated with highest degree-are discrete. This allows us to sort individuals into cells based upon these characteristics. Then we can express the overall average log wages of men in the minority group $G_{j}$ as

$$
E\left(y \mid G_{j}\right)=\sum_{X} p_{j x} E\left(y \mid G_{j}, X=x\right),
$$

where $E\left(y \mid G_{j}, X=x\right)$ is the expected earnings of men in the $G_{j}$ with characteristic $X=x$, and $p_{j x}$ is the proportion of men in $G_{j}$ with characteristic $X=x$. These values can be consistently estimated using the cell proportions and cell means for men in $G_{j}$. Similarly, for non-Hispanic white men we can write

$$
E(y \mid W)=\sum_{X} p_{W x} E(y \mid W, X=x) .
$$

Substituting into equation (1) gives

\footnotetext{
${ }^{9}$ See Heckman, Ichimura, and Todd (1998) for a helpful discussion of the assumptions implicit in this method.
}

$$
\begin{aligned}
E\left(y \mid G_{j}\right)-E(y \mid W)= & \sum_{X} p_{j x} E\left(y \mid G_{j}, X=x\right) \\
& -\sum_{X} p_{W x} E(y \mid W, X=x) .
\end{aligned}
$$

We can further decompose this equation through the use of a term that estimates the missing counterfactual: what would we expect the earnings of minority men to be if they kept the same distribution of covariates but were treated as non-Hispanic white men in the labor market? This is estimated using the average earnings of non-Hispanic white men, with their average earnings in each cell staying the same but their proportions across cells changed to the proportions for men in the group $G_{j}$. We can add and subtract this term

$$
\sum_{X} p_{j x}\{E(y \mid W, X=x)\}
$$

in equation (2), giving

$$
\begin{aligned}
E\left(y \mid G_{j}\right)-E(y \mid W)= & \sum_{X} p_{j x}\left\{E\left(y \mid G_{j}, X=x\right)\right. \\
& -E(y \mid W, X=x)\} \\
& -\sum_{X}\left\{p_{w x}-p_{j x}\right\} E(y \mid W, X=x) .
\end{aligned}
$$

The first term is the effect of "treatment on the treated" as described previously - the portion of the gap that is "unexplained" by the covariates. The second term is associated with group differences in the proportions of individuals across cells, that is, the portion of the gap that is "explained" by the covariates.

Thus our decompositions are very much in the spirit of the Blinder-Oaxaca decomposition traditionally used in studies of gender, racial, and ethnic wage gaps; see Altonji and Blank (1999) for a review and discussion. There are, however, two distinctive aspects of our work we wish to emphasize.

First, we focus on the effect of "treatment on the treated" by averaging over the supports of the characteristics of interest within the minority group for which we are estimating a wage gap, not the non-Hispanic white distribution or a pooled distribution. As noted above, our framework could also be used to generate a parallel decomposition,

$$
\begin{aligned}
E(y \mid W)-E\left(y \mid G_{j}\right)= & \sum_{x} p_{W x}\{E(y \mid W, X=x) \\
& \left.-E\left(y \mid G_{j}, X=x\right)\right\} \\
& -\sum_{x}\left\{p_{j x}-p_{W x}\right\} E\left(y \mid G_{j}, X=x\right),
\end{aligned}
$$

in which the majority group covariate distribution is used to estimate the unexplained portion of the gap. That portion could be interpreted as the average difference in wages that 
non-Hispanic white men would experience if they were members of the minority group (that is, the effect of "treatment on the untreated"). Often estimates from both of these two parallel decompositions are presented; the result is said to be the "indeterminacy" of the Blinder-Oaxaca decompositions, though we find such terminology to be misleading. The two decompositions are estimating potentially different parameters - the "treatment on the treated" and the "treatment on the untreated." The first of these decompositions seems more intuitively appealing if the goal of the exercise is to determine the effect of market discrimination on the people being discriminated against. There is an additional practical consideration: given our nonparametric approach and that we use detailed education measures (highest degree and major), we would encounter very serious lack of support if we were to undertake the alternative decomposition. This decomposition would require estimates of the missing counterfactual for non-Hispanic white men: the expected wage of white men if they instead were members of each minority group. These estimates require data on minority men with similar characteristics to white men. In our data, there are substantial areas of the white distribution for which there is no support in the minority distributions. ${ }^{10}$

Second, by adopting a nonparametric approach, we avoid problems that can arise in the use of the usual parametric Blinder-Oaxaca decomposition models. The issue at hand receives careful treatment in recent work by Barsky et al. (2002), in which the authors demonstrate that the typical parametric Blinder-Oaxaca approach leads to serious errors in estimating the portion of the black-white wealth gap that is due to differences in earnings. These errors occur as the consequence of two problems. The first problem is one of support; virtually all of the households with high levels of assets are white, and black households are over-represented among households with very low levels of assets. The second problem is the misspecification of the parametric model of the relationship between earnings and wealth. The wealth equation for whites is heavily influenced by values at the high end of the income distribution, whereas blacks with high levels of wealth are sparse enough that the model is not well estimated in that region of the income distribution. Thus parameters from the black equation are used to make predictions outside the support of the data, and parameters from the white model do not provide a good fit to the white data over regions of the income distribution where the support for black households lies. Barsky et al. (2002) demonstrate that these factors combine to create serious errors in estimates of the wealth gap and the amount of the gap "explained" by the racial differences in income distribution.

\footnotetext{
${ }^{10}$ If we were content to match on highest degree only (not field of study), this problem would not arise. In the decomposition that we do present, there is an occasional problem with support, but it is not usually serious, because the number of non-Hispanic white men in the sample is very large.
}

Similar concerns may well pertain to our problem. By using a matching model, we avoid assumptions that may be difficult to sustain, such as the parametric assumption that the age-wage profile is the same for each highest-degreemajor category within the demographic group. The recent work of Racine and Greene (2002) and Heckman, Lochner, and Todd (2003) demonstrates that standard parametric models do not fit earnings or wage data well.

Some studies of minority wage gaps include extensive controls that we do not include, for example, family structure indicators, experience, and occupation or job characteristics. As mentioned in the introduction, because many of these variables may be endogenous with respect to labor market outcomes and because our goal is to focus explicitly on premarket characteristics, we leave these variables out of our analysis [see the related discussion by Altonji and Blank (1999)].

\section{B. Standard Errors}

To estimate standard errors for the results of the matching model we use a nonparametric bootstrap, which has two advantages. First, it allows us to incorporate the variability of the matching cell sizes due to random sampling and nonresponse. Second, it allows us to take advantage of the variance-reducing attributes of the stratified sampling design of the NSCG. In order to estimate the effect of "treatment on the treated," we average the differences in mean log wages over the distribution of age, highest degree, and field of study for each minority group of interest. The weighted counts within each of the discrete cells of this distribution are random variables, and the bootstrap allows us incorporate the variance of these cell sizes into the overall variance estimate. In addition, the matching cell sizes are affected by unit and item nonresponse. These sources of variation are taken into account by resampling the original sample, before any exclusions are made from unit or item nonresponse or from being out of scope for the survey or this analysis. Then, the exclusions are applied to each resampled data set, resulting in a random effective sample size and a random matching cell size. This procedure is an alternative to that presented by Canty and Davison (1999), who also recommend resampling the full original sample but then reestimating the adjusted sampling weights within each resampled data set (so that the final sampling weights are random variables). ${ }^{11}$ As is common for large public-use data sets, we did not have the information necessary to re-create the adjustments. Our alternative leaves the individual sampling weights fixed but varies the sum and thus the relative weight of each sampled person in the resampled data sets.

Stratified sample designs are variance-reducing as long as the variance within sampling strata is smaller than the variance between sampling strata. The variance is reduced

\footnotetext{
${ }^{11}$ Canty and Davison (1999) found that incorporating the variance of these random adjusted sampling weights substantially changed their variance estimates when estimating common labor force outcomes.
} 
Table 1.-Degrees and College Majors among Men Aged 25 to 60

\begin{tabular}{|c|c|c|c|c|}
\hline \multicolumn{5}{|c|}{ (A) } \\
\hline \multirow[b]{2}{*}{ Highest Degree } & \multicolumn{4}{|c|}{ Distribution (\%) } \\
\hline & White & Black & Hispanic & Asian \\
\hline Bachelor's & 63.34 & 68.28 & 65.44 & 54.24 \\
\hline Master's & 22.89 & 22.57 & 20.90 & 27.13 \\
\hline Professional degree & 9.00 & 5.69 & 9.58 & 10.02 \\
\hline $\mathrm{PhD}$ & 4.76 & 3.46 & 4.08 & 8.62 \\
\hline$N$ & 56,524 & 4,887 & 4,103 & 7,633 \\
\hline
\end{tabular}

(B)

\begin{tabular}{|c|c|c|c|c|c|}
\hline \multirow[b]{2}{*}{ Bachelor's Major } & \multirow{2}{*}{$\begin{array}{c}\text { Mean Wage for } \\
\text { Bachelor's Degree } \\
(\$ / \mathrm{h})\end{array}$} & \multicolumn{4}{|c|}{ Distribution (\%) } \\
\hline & & White & Black & Hispanic & Asian \\
\hline Engineering & 24.73 & 12.72 & 5.97 & 13.73 & 29.75 \\
\hline Mathematical sciences & 21.75 & 2.53 & 2.70 & 2.10 & 3.28 \\
\hline Business \& economics & 21.38 & 28.10 & 25.16 & 23.79 & 21.07 \\
\hline Physical sciences & 19.74 & 4.57 & 3.05 & 3.50 & 7.33 \\
\hline Social sciences & 19.24 & 13.91 & 17.89 & 13.79 & 7.42 \\
\hline Health professions & 19.09 & 2.61 & 2.48 & 3.53 & 5.20 \\
\hline Engineering technology & 19.00 & 1.88 & 2.41 & 2.12 & 2.45 \\
\hline Computer sciences & 18.49 & 1.75 & 1.25 & 2.48 & 3.64 \\
\hline Life sciences & 17.44 & 4.94 & 4.54 & 6.04 & 5.22 \\
\hline Humanities & 17.14 & 6.76 & 5.15 & 7.38 & 4.43 \\
\hline Education & 17.05 & 8.10 & 14.04 & 8.80 & 2.39 \\
\hline Professional degrees & 17.01 & 5.33 & 8.08 & 5.96 & 2.18 \\
\hline Agricultural sciences & 16.47 & 2.58 & 1.88 & 2.82 & 2.68 \\
\hline Fine arts & 16.13 & 3.30 & 3.50 & 3.01 & 1.77 \\
\hline Major not elsewhere classified & - & 0.91 & 0.92 & 0.96 & 1.20 \\
\hline Dissimilarity index $(\%)$ & & 0.00 & 20.03 & 13.55 & 31.27 \\
\hline
\end{tabular}

(C)

\begin{tabular}{lcccc} 
& \multicolumn{3}{c}{ Mean Fraction Female within Undergraduate Major (\%) } \\
\cline { 2 - 5 } & White & Black & Hispanic & Asian \\
\hline Men & $33.89 \%$ & $39.15 \%$ & $35.11 \%$ & $26.45 \%$ \\
Women & $61.44 \%$ & $59.84 \%$ & $57.60 \%$ & $51.99 \%$
\end{tabular}

Notes: The data are weighted to take account of sample stratification. Wage estimates are for all men whose highest degree is a bachelor's reporting positive earnings for the year with nonimputed data on earnings, weeks worked, and usual hours of work per week. Other estimates are based on the sample of men (or men and women) with nonimputed gender, highest degree, and major who were in the NSCG. The dissimilarity index is the sums the fraction of non-Hispanic white men in a major cell minus the fraction of the minority group in the major cell over all of the major cells.

by calculating the overall variance as the (weighted) sum of the variance within each stratum so that the between-strata variance is omitted. This variance-reduction property is incorporated into the bootstrap by resampling independently within each stratum to create each resampled data set. Because this simple within-strata procedure has been shown to be biased with simple parameters when some of the strata are small, we use a modified bootstrap method, referred to as the with-replacement bootstrap in Shao and Tu (1995, p. 247). The modification consists of resampling $n_{h}-1$ observations instead of $n_{h}$ observations from each stratum, with replacement, where the stratum size is $n_{h}$ for stratum $h$. The standard errors presented here are based on 1,000 bootstrap iterations. See Haviland (2003) for a discussion with more details.

\section{Results}

Table 1 provides our first piece of evidence concerning the heterogeneity of college education, and the potential for these differences to influence observed minority wage dif- ferentials. Panel A shows that among the college-educated, Asians are more likely than non-Hispanic whites to pursue graduate degrees, and black and Hispanic men are somewhat less likely. Among Hispanics who do pursue graduate degrees, however, an especially high fraction earn a professional degree (these are primarily JDs and MDs, but include also a few smaller degree categories such as DDS and DVM). Panel B shows large racial/ethnic differences in choices of college major at the bachelor's level. ${ }^{12}$ The index of dissimilarity indicates that approximately $14 \%$ of Hispanic men, $20 \%$ of black men, and $31 \%$ of Asian men would need to change their major to match the distribution of majors among whites. Although Hispanic men have a major distribution similar to non-Hispanic whites, Asians are considerably more likely to major in engineering, whereas black men tend to be under-represented in engineering and

${ }^{12}$ In Panel B of table 1 we aggregate our major categories. Our subsequent analysis exploits data on more than 140 majors; we aggregate only a group of (very small) majors that the Census Bureau suppressed to keep the identities of the respondents confidential. 
TABLE 2-MinoRity Wage GaPS

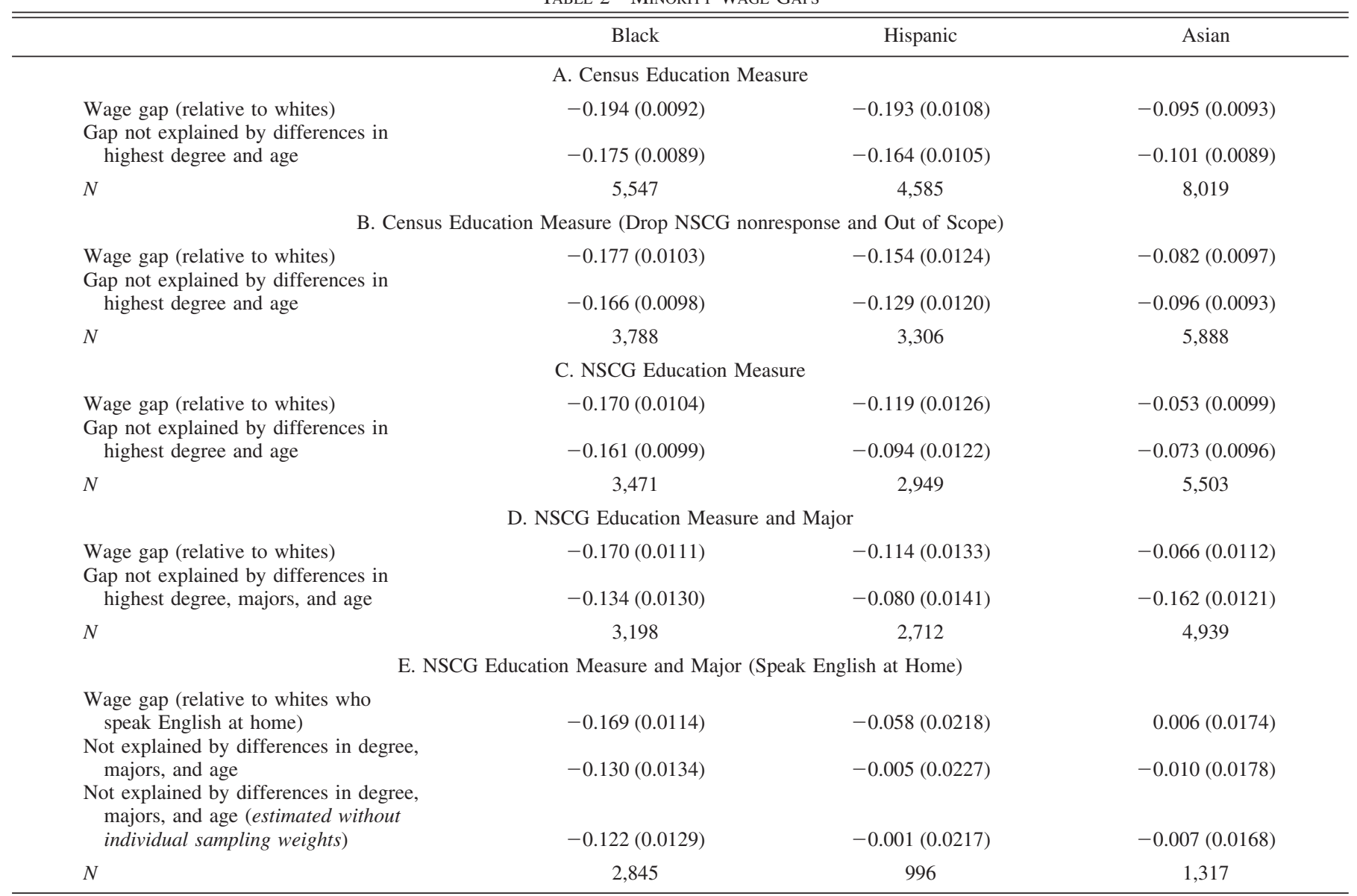

Notes: All differentials are computed relative to white non-Hispanic men. In panels A and B, workers are matched on their age and Census-reported highest degree. In panel C, workers are matched on their age and NSCG-reported highest degree. In panel D, we additionally match workers on their highest-degree major field of study. Finally, in panel E, we match workers as in panel D, but report differences only for those workers who speak only English at home. Bootstrapped standard errors are reported in parentheses. In panels A-C, all minority men have exact matches. In panel D the percentages of minority men with exact matches and thus retained in the sample are $92.1 \%, 92.0 \%$, and $89.8 \%$ for black. Hispanic, and Asian men, respectively. In panel E, the rates are $91.9 \%, 92.3 \%$, and $92.3 \%$

over-represented in education. These patterns are seen again in panel $\mathrm{C}$, which shows the mean fraction of females within undergraduate major for each group. ${ }^{13}$ This table shows that Asian men choose majors that on average have a lower fraction of women than non-Hispanic white men's majors, whereas black men choose majors that on average have a higher fraction of women.

A key goal of our empirical analysis is to discover how much of the observed racial/ethnic differences in wages are attributable to educational factors-differences in college degrees and major (along with age). As a starting point we present, on the first line of table 2, the raw gap as measured using wage data from the 1990 Census provided by the men who were selected for the NSCG sample (men who reported having a bachelor's degree or higher in their 1990 Census returns and who were selected to be in the NSCG). ${ }^{14}$ Even

\footnotetext{
${ }^{13}$ Brown and Corcoran (1997) use this mean-fraction-female variable in their wage regressions as a univariate alternative to a set of dummy variable for majors. It is calculated by first obtaining the fraction female within each major represented in the sample and then taking the mean of these fractions over the individuals within each demographic group.

${ }^{14}$ The NSCG files include a number of variables recorded in the respondents' original 1990 Census forms. In all of our analyses our wage
}

though we are restricting attention to individuals who report a college degree or higher in the Census, substantial gaps are found. In comparison with non-Hispanic white men, black and Hispanic men earn approximately $19 \%$ less, and Asians earn approximately $10 \%$ less.

The second line of panel $\mathrm{A}$ of table 2 provides estimates of the gap remaining after matching on age and educational levels as reported on the Census data that are included as part of the NSCG data files. Differences in age and highest degree account for none of the observed Asian-white wage gap, and account for only 0.019 log points of the blackwhite wage gap and $0.029 \log$ points of the wage gap between Hispanics and non-Hispanic whites.

Our first interesting finding comes from comparing the wage gaps as estimated with Census education data (the first line of panel A) with the wage gaps as estimated with education data drawn by the NSCG itself (the first line of panel C). The estimated wage gap falls modestly for blacks

data come from these 1990 Census data. The raw gap is obtained by taking the (weighted) average of the log wages for the demographic group of interest and subtracting the (weighted) average of the log wages for white, non-Hispanic men. 
(from 0.194 to 0.170 ), but substantially for Hispanics (from 0.193 to 0.119 ) and for Asians (from 0.095 to 0.053 ). The first line of panel B shows that some of this drop is due to the lower wages of Hispanic and Asian men who did not respond to the NSCG or were found to be out of scope due to problems such as misreported age or emigration. Elsewhere (Black, Sanders, \& Taylor, 2003) we argue that the remainder of the drop is due to very substantial measurement error in the reporting of education in the U.S. Census. As we have mentioned, in collecting the NSCG, the NSF and Census Bureau were particularly concerned about the respondents' education, and devoted much effort to ensuring the accuracy of the education responses, asking about the respondents' college or university and about the major and minor fields of study. Because the information is sufficiently detailed, it seems plausible that the education-level data reported by college-educated men in the NSCG are essentially correct. By comparing the NSCG education reports and the Census education reports, we discover substantial measurement error. Indeed, $7.4 \%$ of those reporting a bachelor's degree in the Census, $2.3 \%$ of those reporting a $\mathrm{PhD}$ in the Census, and $17.0 \%$ of those reporting a professional degree in the Census report having no college degree in the NSCG. ${ }^{15}$ More importantly, education misreports are more common among minority groups than among non-Hispanic whites. Misreports were especially common for Hispanics and Asians. ${ }^{16}$ The consequence is that a disproportionate fraction of Hispanic and Asian men in the U.S. Census who report having a college degree in fact have no such degree. On average these latter men have low earnings, and this in turn leads to an overestimate of the race/ethnicity wage gap.

Panel $\mathrm{C}$ of table 2 shows that only a modest part of the wage gap is explained for blacks and Hispanics by differences in highest degree and age, and for Asians the unexplained gap actually increases (by $0.020 \log$ points). Comparing panel $\mathrm{D}$ with panel $\mathrm{C}$, we notice that conditioning on college major does not greatly affect inferences drawn about Hispanic men; the log point gap explained increases only slightly, from 0.025 to 0.034 . For blacks, in contrast, the log point gap explained rises from 0.009 to 0.036 . American Asians disproportionately earn degrees in fields that are well compensated. Thus, the unexplained gap (i.e., that gap that remains when we compare men with identical ages, degrees, and majors) is larger than the initial gap.

\footnotetext{
15 These percentages do not include respondents whose educational level was imputed on the Census or those who did not complete the NSCG survey. The percentages are weighted to reflect the stratified sampling of the NSCG. For our analyses we were careful to allow appropriately for the small number of individuals who received a degree between 1990 (when the Census education data were drawn) and 1993 (when the NSCG education data were reported). In all cases we are interested in individuals' educational levels in 1990.

${ }^{16}$ In Black et al. (2003) we provide strong evidence that education misreports in the Census are more common for those with poorer selfreported language ability. Thus it is not surprising that misreports are more common among Asians and Hispanics, as these groups include a disproportionate number of immigrants.
}

Panel E restricts attention to individuals who indicate that they "speak English at home." The striking results from panel E are for Hispanics and Asians. For Hispanics and Asians who speak English at home, the unexplained wage gaps are almost exactly 0 ; these men have wages that equal those of same-aged white men who have similar degrees and majors. For blacks a substantial gap, approximately 13 percentage points, remains. We explore each of these findings in more detail below.

Before turning to further explorations, though, we briefly discuss two relevant methodological issues. The first issue revolves around our use of nonparametric methods. A common alternative in the estimation of race/ethnicity wages is the more restrictive regression-based Blinder-Oaxaca method (see, for example, Altonji \& Blank, 1999). One might wonder if our inferences would differ had we used this latter methodology. Calculating regression-based unexplained wage gaps comparable to our nonparametric gaps entails two steps: (1) estimate a log-wage regression (with age entered as a quadratic and degrees and majors as dummy variables) using the non-Hispanic white sample, and then (2) use the resulting coefficients to calculate a predicted log wage for members of the minority group, and compare these predicted values with the observed wages.

When we undertake this exercise we estimate unexplained gaps of -0.128 for blacks, -0.090 for Hispanics, and -0.156 for Asians-estimates that are very similar to the comparable results reported in panel D of table 2. When we include a dummy variable for speaking English at home in the regression (a typical method for controlling for a binary factor in parametric regression), we estimate unexplained gaps of -0.122 for blacks, -0.027 for Hispanics, and -0.084 for Asians-inferences that are very different than the comparable nonparametric estimates reported in panel $\mathrm{E}$ of table 2. Of course, if we were to use a more flexible functional form in the log-wage regression, the Blinder-Oaxaca decomposition would likely yield results closer to our nonparametric estimates. Our findings serve to emphasize the importance of flexibility in specification within decomposition methods, the most flexible being the exact matching method used here.

The second concern, which has been discussed in several prominent analyses of race/ethnicity wage gaps, is that the "real," or "potential," wage gap will differ from the observed wage gap if a disproportionate fraction of minority workers are not working, and if moreover nonworking individuals are in general those who would likely report low wages if they were working (see, for example, Butler \& Heckman, 1977; Brown, 1984; Neal \& Johnson, 1996). Because we focus on college-educated men under age 60 , this concern is perhaps less relevant than in studies that examine the entire labor force. Nonetheless some notable racial/ethnic differences exist: in the NSCG, among men who speak English at home, the rates at which men fail to report earning positive wages are approximately $15 \%$ for 
non-Hispanic white men, Hispanic men, and Asian men, and $21 \%$ for black men. Only a small part of this disparity owes to differences in the proportion that is not working ( $2.2 \%$ of non-Hispanic white men, $3.9 \%$ of black men, $2.9 \%$ of Hispanic men, and $2.4 \%$ of Asian men). The larger difference is among those in the NSCG choosing not to report their wages on the 1990 Census- $6.5 \%$ of non-Hispanic white men, $13.3 \%$ of black men, $6.8 \%$ of Hispanic men, and $5.7 \%$ of Asian men.

To address the concern that the potential wages of these men may differ systematically by race, we nonparametrically imputed for those not reporting positive wages, and then we reestimated the wage gaps in table $2 \mathrm{E}$ using both reported and imputed wages. We imputed the wages by matching those without wages with those with wages of the same race, age, highest degree, and major associated with the highest degree and assigning them the mean wage among their matched group. ${ }^{17}$ This method does not address whether those not working or not reporting wages have wage incomes or potential wage incomes that differ from others of the same age, race, highest degree, and major associated with the highest degree. It does address whether those not working or not reporting wages have a different distribution across age, highest degree, and major by race. The potential wage gaps relative to non-Hispanic whites (found using both those who reported positive wages and the imputed potential wages for those who did not) are well within 1 standard deviation of the estimates reported in table 2. Thus, the estimates we report in table 2 may not be substantially biased by the exclusion of those not working, those reporting zero wages, or those not reporting wages.

\section{A. Hispanics and Asians: The Role of Speaking English at Home}

A striking finding reported on the bottom line of table 2 is that among workers who solely speak English at home, Asian and Hispanic men's wages are virtually identical to those of comparable white men. In contrast, men who do not speak English at home earn considerably less than their English-speaking white counterparts, or their counterparts from the same ethnic group who do solely speak English at home-individuals who presumably have stronger English skills and possibly higher levels of assimilation. Our result mirrors Trejo (1997), who finds very large returns to English ability among Mexican Americans.

We explore this finding in greater detail by dividing the sample, for each race/ethnicity group, into four mutually exclusive subgroups: by immigration status (immigrant or nonimmigrant) and by language spoken at home (English or language other than English). Panel A of table 3 shows the

\footnotetext{
17 The Census Bureau imputes wages for those who leave the wages question blank. The imputation is based on age, race, educational level, and several other variables. Our imputations may be better, because the NSCG likely has less misreporting of education than the Census and because we use information on majors not reported in the Census.
}

distribution for each group. A large number of Hispanicsboth immigrant and nonimmigrant—-speak a language other than English at home. Most immigrant Asian men speak a language other than English at home, whereas most nonimmigrant Asian men speak only English at home.

Panel B of table 3 reports the unexplained wage gaps for each race/ethnic minority relative to a new baseline majority-non-Hispanic white men who speak English at home. Among those who speak English at home, estimated wage gaps are quite similar for non-Hispanic whites, Hispanics, and Asians-immigrant and nonimmigrant alike. Non-Hispanic white immigrants who speak English at home in fact earn slightly more than non-immigrant whites. Those who speak a language other than English at home generally earn less. ${ }^{18}$

When we restrict attention to men who speak English at home, Asian and Hispanic men earn the same as nonHispanic white men. One natural interpretation is that the observed wage gaps between Asian and Hispanic men and non-Hispanic white men are in general the result of differences in productive skills, not discrimination. In this view, the earnings gap for Asian and Hispanic men who speak a language other than English at home is the result of differences in language skills (and perhaps unobserved differences in other forms of human capital) ${ }^{19}$ Alternatively, the relevant form of discrimination may not be based primarily on race or ethnicity, but may instead stem from discrimination based on cultural differences. The majority group may not object to employing or working with Hispanics or Asians as long as they have adopted the culture of the majority group. ${ }^{20}$

\footnotetext{
${ }^{18}$ Though there is an active debate on whether the skills of recent immigrants to the United States have declined recently, the literature uniformly documents improvements in earnings of immigrants as they spend more time in the United States and, presumably, their English skills improve [Borjas (1994) reviews the literature]. Our results seem consistent with this generalization.

${ }^{19}$ As discussed by Zeng and Xie (2004), one source of unobserved differences in human capital is the quality of higher education, which might be related to whether an individual was educated in the United States or abroad. In our sample, among Hispanics who do not speak English at home, 25\% attained their highest degree at a foreign college or university. For these individuals the unexplained log wage gap is -0.386 , compared with -0.073 for those whose degree was earned in the United States. Similarly, $42 \%$ of Asians who do not speak English at home earned their highest degree abroad. For this group, the unexplained log wage gap is -0.315 , which compares to -0.164 for those whose highest degree was earned in the United States. Of course, these differences might be due to differences in the programs of study, or might be due to the improved English language skills among those who studied in the United States.

${ }^{20}$ A third possibility is that the geographical distributions of Hispanic and Asian men who speak English at home may contribute to their wage being higher than otherwise comparable white men. To explore this possibility we matched these Hispanic and Asian men to non-Hispanic white men of the same age, highest degree, and major who additionally lived in the same large city, or same state if they did not live in a large city. Although there was a substantial lack of support (we could not match almost half of the Hispanic and Asian men) the average gaps for those with matches were also not statistically significantly different from 0 . It seems that location is not driving these results.
} 
TABle 3.-Language and Immigration Status

\begin{tabular}{|c|c|c|c|c|c|}
\hline \multicolumn{6}{|c|}{ A. Language Spoken at Home and Immigration Status by Race and Ethnicity } \\
\hline & \multicolumn{5}{|c|}{ Proportion $(\%)$} \\
\hline & \multicolumn{2}{|c|}{ Nonimmigrants } & \multicolumn{2}{|c|}{ Immigrants } & \multirow[b]{2}{*}{ Total } \\
\hline & $\begin{array}{l}\text { Speaks only } \\
\text { English at } \\
\text { home }\end{array}$ & $\begin{array}{l}\text { Speaks language } \\
\text { other than } \\
\text { English at home }\end{array}$ & $\begin{array}{l}\text { Speaks only } \\
\text { English at } \\
\text { home }\end{array}$ & $\begin{array}{l}\text { Speaks language } \\
\text { other than } \\
\text { English at home }\end{array}$ & \\
\hline Whites & 93.81 & 2.16 & 2.36 & 1.67 & 100.00 \\
\hline Blacks & 85.08 & 3.35 & 5.87 & 5.70 & 100.00 \\
\hline Hispanics & 28.85 & 28.02 & 6.47 & 36.65 & 100.00 \\
\hline \multirow[t]{5}{*}{ Asians } & 17.96 & 3.40 & 8.37 & 70.28 & 100.00 \\
\hline & \multicolumn{4}{|c|}{ B. Wage Gaps by Language Spoken at Home, Immigration Status, and Race and Ethnicity } & \\
\hline & \multicolumn{4}{|c|}{ Differential } & \\
\hline & \multicolumn{2}{|c|}{ Nonimmigrants } & \multicolumn{2}{|c|}{ Immigrants } & \\
\hline & $\begin{array}{l}\text { Speaks only } \\
\text { English at } \\
\text { home }\end{array}$ & $\begin{array}{l}\text { Speaks language } \\
\text { other than } \\
\text { English at home }\end{array}$ & $\begin{array}{l}\text { Speaks only } \\
\text { English at } \\
\text { home }\end{array}$ & $\begin{array}{l}\text { Speaks language } \\
\text { other than } \\
\text { English at home }\end{array}$ & \\
\hline \multirow[t]{3}{*}{ Whites } & -0.001 & -0.077 & 0.028 & -0.127 & \\
\hline & $(0.0003)$ & $(0.0341)$ & $(0.0122)$ & $(0.0209)$ & \\
\hline & {$[n=34,958]$} & {$[n=789]$} & {$[n=2,116]$} & {$[n=1,641]$} & \\
\hline \multirow[t]{3}{*}{ Blacks } & -0.126 & -0.072 & -0.201 & -0.334 & \\
\hline & $(0.0131)$ & $(0.0576)$ & $(0.0494)$ & $(0.0681)$ & \\
\hline & {$[n=2,627]$} & {$[n=103]$} & {$[n=211]$} & {$[n=205]$} & \\
\hline \multirow[t]{3}{*}{ Hispanics } & -0.007 & -0.093 & -0.007 & -0.157 & \\
\hline & (0.0233) & $(0.0221)$ & $(0.0610)$ & (0.0293) & \\
\hline & {$[n=828]$} & {$[n=795]$} & {$[n=158]$} & {$[n=872]$} & \\
\hline \multirow[t]{3}{*}{ Asians } & -0.006 & -0.049 & -0.017 & -0.234 & \\
\hline & (0.0199) & $(0.0502)$ & $(0.0381)$ & $(0.0157)$ & \\
\hline & {$[n=933]$} & {$[n=175]$} & {$[n=376]$} & {$[n=3,318]$} & \\
\hline
\end{tabular}

Notes: In panel A, the data are weighted to take account of sample stratification. Estimates are from nonparametric regressions. All differentials are computed relative to white non-Hispanic men who speak English at home. The point estimates for white men are nonzero because the comparison group contains both immigrants and nonimmigrants. We match workers on their age, NSCG-reported highest degree, and highest-degree major field of study. Bootstrapped standard errors are reported in parentheses. Going across the rows, the rates matched are: $100 \%, 90.0 \%, 100 \%, 86.8 \% ; 92.1 \%, 89.6 \%, 88.7 \%, 86.1 \% ; 92.7 \%, 92.4 \%$, $89.8 \%, 89.4 \% ; 93.0 \%, 92.1 \%, 90.4 \%, 86.8 \%$.

For interest's sake, we calculated unexplained log wage gaps for each of the largest national-origin classifications within the Asian and Hispanic samples. Among the Asian groups (Chinese, Filipino, Japanese, Asian Indian, and Korean origin) the absolute value of the estimated unexplained log wage gaps is for each group very close to $0-0.02$ or less. Among Hispanics who speak English at home, the estimated gap is similarly small for men of Mexican origin $(-0.018)$, but -0.067 for those of Puerto Rican origin, and 0.040 for those of Cuban origin. ${ }^{21}$

\section{B. Blacks: Parental Education and Regional Differences}

As the results from table 2 indicate, wages of black men are approximately 13 percentage points lower than wages of similarly aged white men with the same college degree and major. Though this is a substantial reduction from the mean

\footnotetext{
${ }^{21}$ Among Hispanics in the United States, there appear to be substantial differences in the rates of college degree attainment by national origin. For example, using 1990 PUMS data, we estimate that among adult Hispanic men, $64 \%$ are of Mexican origin, $13 \%$ Puerto Rican origin, and 6\% Cuban origin. By comparison, in the NSCG the corresponding percentages are $43 \%$ for Mexican, $12 \%$ for Puerto Rican, and $12 \%$ for Cuban. In any event, it is worth noting that because the rates of college degree attainment are generally low for Hispanic men in the United States, the men analyzed here are a rather select group of Hispanics.
}

differential estimated from the Census data, less than a third of the differential is explained by racial differences in age, degree, and major (or measurement error in recording highest degree). It is clearly important to understand the source of this unexplained black-white gap.

Our first approach is to examine the wage gap by the education of respondents' parents. For this analysis, we divide respondents into three groups according to the education level of their less-educated parent (usually the respondent's mother): less than high school, high school graduate, and at least some college. The motivation for this analysis stems from a concern about heterogeneity in precollege preparation. Card and Krueger (1992a) document that especially for schoolchildren born prior to 1940, the quality of the segregated public schools in much of the Southern United States was much worse for blacks than for whites. For example, blacks in the 1920-1929 birth cohort who attended schools in Alabama, Georgia, Louisiana, Mississippi, or South Carolina typically were in classes that were $30 \%$ to $50 \%$ larger than those of white students and received instruction from teachers who earned less than half as much as teachers in white schools. Many of the older Southern-born black men in our sample were likely educated in conditions of extreme educational inequality. Many 
Table 4.-Racial Wage Gaps by Parents' Education AND REGION OF BIRTH

\begin{tabular}{|c|c|c|}
\hline \multirow{2}{*}{$\begin{array}{l}\text { Education of the } \\
\text { Less-Educated Parent }\end{array}$} & \multicolumn{2}{|c|}{ Gap } \\
\hline & Black & White \\
\hline \multicolumn{3}{|c|}{$\begin{array}{c}\text { A. Southern-Born: Wage Gap Not Explained by Differences in } \\
\text { Age, Degree, and College Major; English-Speaking Only }\end{array}$} \\
\hline Less than high school & $\begin{array}{c}-0.242 \\
(0.0361) \\
{[n=649]}\end{array}$ & $\begin{array}{c}-0.090 \\
(0.0301) \\
{[n=1,376]}\end{array}$ \\
\hline High school & $\begin{array}{c}-0.206 \\
(0.0486) \\
{[n=277]}\end{array}$ & $\begin{array}{c}-0.058 \\
(0.0227) \\
{[n=2,075]}\end{array}$ \\
\hline Some college or more & $\begin{array}{c}-0.184 \\
(0.0537) \\
{[n=173]}\end{array}$ & $\begin{array}{c}-0.036 \\
(0.0236) \\
{[n=1,853]}\end{array}$ \\
\hline \multicolumn{3}{|c|}{ B. Not Southern-Born } \\
\hline Less than high school & $\begin{array}{c}-0.205 \\
(0.0488) \\
{[n=333]}\end{array}$ & $\begin{array}{c}-0.074 \\
(0.0191) \\
{[n=4,972]}\end{array}$ \\
\hline High school & $\begin{array}{c}-0.125 \\
(0.0466) \\
{[n=355]}\end{array}$ & $\begin{array}{c}-0.014 \\
(0.0121) \\
{[n=9,427]}\end{array}$ \\
\hline Some college or more & $\begin{array}{c}+0.020 \\
(0.0464) \\
{[n=247]}\end{array}$ & $\begin{array}{c}0 \\
{[n=9,390]}\end{array}$ \\
\hline
\end{tabular}

Notes: Estimates are from nonparametric regressions. All differentials are computed relative to white non-Hispanic men who were not born in the South and whose parents had attended at least some college. In both panels, we match workers on their age, NSCG-reported highest degree, and their highest degree major field of study. Sample limited to those who speak English at home. Bootstrapped standard error are reported in parentheses. In panel $\mathrm{A}$, the matching rates for men whose parents have increasing re $67.4 \%, 76.5 \%$, and $77.6 \%$ for black (n) men. In panel B, the matching rates are $68.4 \%, 71.6 \%$, and $77.2 \%$ for black men and $67.0 \%, 76.7 \%$, and $100 \%$ for white men.

of the younger Southern-born black men have parents who were educated in these segregated schools.

With this background in mind, we also divide out sample into those born in the South and those not born in the South. ${ }^{22}$ In this analysis, we use as the benchmark group men who have the following characteristics: they are nonHispanic white, not born in the South, and both parents had some college education. ${ }^{23}$ From panel A of table 4 we notice Southern-born men generally earn less than men in this benchmark group. For both black and white Southern-born men, we see only a weak relationship between parents' education and wages (which is not statistically significant for black men).

For blacks not born in the South, however, a different and intriguing pattern emerges. Black men with well-educated parents have much smaller average wage gaps than men with poorly educated parents. For black men born to college-

\footnotetext{
${ }^{22}$ We define Southern states as Alabama, Arkansas, Florida, Georgia, Kentucky, Louisiana, Mississippi, Missouri, North Carolina, South Carolina, Tennessee, Texas, and Virginia. We refer to individuals born elsewhere as being "not born in the South" or as "Northern-born."

${ }^{23}$ With this smaller reference group, the proportion of the other groups who do not have exact matches is larger than in any of our other analyses. For this reason, we also estimated the results using a propensity-score matching model where the educational characteristics were still matched exactly but the estimates for white men were smoothed (using an Epanechnikov kernel of bandwidth 3 years) on age. Though the point estimates from this model differ from those obtained from the exact match, the differences were almost all within twice the standard errors. More importantly, the observed patterns in our results did not change.
}

educated parents, we cannot reject the hypothesis that wages are the same as for comparable white men. Black men with poorly educated parents, in contrast, earn considerably less. Indeed, from panel B we notice for Northern-born men, the "class wage gap" between black men with parents who had some college and those whose parents did not graduate high school is larger than the overall "race wage gap." ${ }^{4}$

Ascertaining the proper interpretation of these results is difficult. A few points, however, merit mention. First, these results may also pose difficulties for those who view discrimination as arising solely from the color of workers' skin. Northern-born black men who have college-educated parents appear to have wages that are very similar to comparable white men. Of course, as we mentioned above (in our discussion of wage gaps for Asians and Hispanics), the predominant form of discrimination may not be racial per se, but rather cultural; the dominant majority group may not object to employing or working with black workers as long as these workers are viewed as having adapted to the majority's culture. Such discrimination may then have less of an effect on wages of second-generation college-educated blacks born in the North than for other groups of black Americans. An alternative explanation is that these patterns stem primarily from unobserved differences in the accumulation of productive human capital, for example, from unobserved differences in the value of productive skills possessed by Southern-born and Northern-born collegeeducated black men.

Although our data do not allow us to distinguish the explanations discussed in the preceding paragraph, we can make observations that place the North-South contrast in some historical perspective. Our focus here is on the large wage gap between Northern-born and Southern-born black men whose parents had some college education. Most of the black men born to college-educated parents in our sample were born between 1945 and $1965 .{ }^{25}$ When these men were school-aged children, the labor market for their collegeeducated parents was very different in the South than in the North. To illustrate this point we use data from the $1 \%$ PUMS of the 1960 U.S. Census to list, in table 5, the occupations of college-educated black men aged 30 to 40 in 1960 for both the South and the North. ${ }^{26}$ We list all occupations that accounted for at least $1 \%$ of the collegeeducated black men in the sample. In the South over one-half of college-educated black men were schoolteachers (who likely were employed in segregated schools), compared with approximately one-fifth in the North. In the

\footnotetext{
${ }^{24}$ One implication of our findings is that parents' education is not a suitable instrument for a child's education in regressions that attempt to estimate the causal effect of education on earnings. Although parents' education is surely correlated with the child's education, it is likely correlated with the error term in the regression as well.

${ }^{25}$ Over $86 \%$ of the Southern-born black men and $89 \%$ of those born elsewhere were born between 1945 and 1965 .

${ }^{26}$ These men are roughly the age we would expect of parents for NSCG respondents who were born between 1945 and 1965.
} 
Table 5.-Occupations of College-Educated Black Men Aged 30 TO 40 By REgION, 1960 CENSUS

\begin{tabular}{lcc}
\hline \hline \multicolumn{1}{c}{ Occupation } & $\begin{array}{c}\text { Northern } \\
\text { Percentage }\end{array}$ & $\begin{array}{c}\text { Southern } \\
\text { Percentage }\end{array}$ \\
\hline Teachers & 19.25 & 50.68 \\
Clerical workers & 10.88 & 6.16 \\
Sports instructors and instructors & 2.09 & 6.16 \\
Social and welfare workers & 5.02 & 0.00 \\
Operatives & 3.35 & 2.05 \\
Professional and technical workers & 2.93 & 0.68 \\
Managers, officials, and proprietors & 2.93 & 0.68 \\
Mail carriers & 0.42 & 4.11 \\
Lawyers and judges & 2.51 & 0.00 \\
Physicians and surgeons & 2.51 & 0.00 \\
Salesmen and sales clerks & 1.67 & 1.37 \\
Accountants and auditors & 2.09 & 0.00 \\
Member of armed forces & 1.67 & 0.68 \\
Electrical engineers & 1.67 & 0.00 \\
Insurance agents and brokers & 1.26 & 0.68 \\
Musicians and music teachers & 0.84 & 1.37 \\
Policeman and detectives & 0.84 & 1.37 \\
Testing technicians & 1.26 & 0.68 \\
Cumulative percentage & 63.18 & 76.71 \\
\hline
\end{tabular}

Notes: The sample is all college-educated black men from the 1\% PUMS of the 1960 Census between 30 and 40 years of age. There are 239 Northern college-educated black men and 146 Southern college-educated black men. The table lists all occupations that account for at least $1 \%$ of the tota sample.

South there were no social workers, lawyers or judges, physicians or surgeons, accountants or auditors, or electrical engineers in the $1 \%$ sample. In contrast, for our nonSouthern sample, these occupations comprised nearly $14 \%$ of all college-educated black men. Among blacks, a college education led to an upper-middle class occupation far more frequently in the North than in the South.

A final issue concerning the contrast between outcomes for Northern- and Southern-born college-educated black men centers on the quality of the colleges these men attended. We have already noted that many of the Southernborn men were likely educated in low-quality primary and secondary public schools. ${ }^{27}$ They may also have been more likely than others in our sample to attend low-quality colleges. Our data set does not allow us to identify the exact colleges attended by respondents, nor do we have any direct information about the quality of the schools from which respondents graduated. Work by Daniel, Black, and Smith (2001), however, confirms that many historically black institutions of higher education, particularly in the South, rank very low along a number of traditional measures of school quality. Using evidence provided in Ehrenberg and Rothstein (1993, table 2) from the NLS Class of 1972, we calculate that among blacks attending college, $66 \%$ of those born in the South attended a historically black institution, compared to $26 \%$ of those who were not born in the South.

In short, on average blacks born in the South had access to schools with poor resources-at both the precollege and college levels-in comparison with Southern-

\footnotetext{
${ }^{27}$ Card and Krueger (1992a) point out that most Southern states continued to operate segregated schools well into the $1960 \mathrm{~s}$, long after the landmark 1954 decision Brown v. Board of Education.
}

born whites and in comparison with blacks born elsewhere (especially, one might surmise, in comparison with Northern-born blacks whose parents were themselves college-educated). To the extent that school quality matters for future earnings, it is not surprising that the unexplained race wage gap is notably higher for Southern-born blacks than for other minorities, including blacks not born in the South. ${ }^{28}$

\section{Differences in Income Distribution}

Returning to our primary findings, reported on the last line of table 2, recall that among men who speak English at home, the mean gap in log wages (relative to non-Hispanic white men) is approximately 0 for Asian men and Hispanic men and is 13 points for black men. Because our matching procedure is nonparametric, a comparison at the mean is only one of many ways in which we could have presented the contrast between wages of a minority group and the majority. In figure 1 we present the entire probability distribution functions.

Panel A plots results for the black men. Recall that for each of 2,835 black men we calculate the difference between that individual's log wage and the average of the log wages of non-Hispanic white men who have identical observed characteristics. The line labeled "black pdf" plots these differences. For comparison we conduct an analogous exercise for the non-Hispanic white men; we calculate for each of these men the difference between his log wage and the average of the log wage of all other non-Hispanic white men who have identical observed characteristics. To make results comparable we then weight these latter differences by age degree major weights calculated using the black distribution. In panels $\mathrm{B}$ and $\mathrm{C}$ we conduct analogous exercises for the Hispanic men and Asian men.

The shape of the black distribution appears to be quite similar to that of the non-Hispanic white distribution-lying to the left by approximately $0.13 \mathrm{log}$ points fairly consistently throughout the range of the distribution. Although the mean of the Hispanic distribution is the same as that of the non-Hispanic white distribution, the Hispanic distribution appears to have slightly thicker tails. The entire Asian distribution is very similar to the non-Hispanic white distribution.

\section{Concluding Remarks}

Our study documents substantial unadjusted wage gaps between college-educated minority men-black, Hispanic, and Asian - and non-Hispanic white men. We find that these wage differences generally appear to be the consequence of differences in premarket factors: age, the levels and types of education, and English fluency and/or assimilation. In par-

\footnotetext{
${ }^{28}$ See Card and Krueger (1992b) for persuasive evidence that the quality of schools affects individuals' future earnings.
} 
Figure 1.-Probability Density Functions of Estimated Wage Gaps

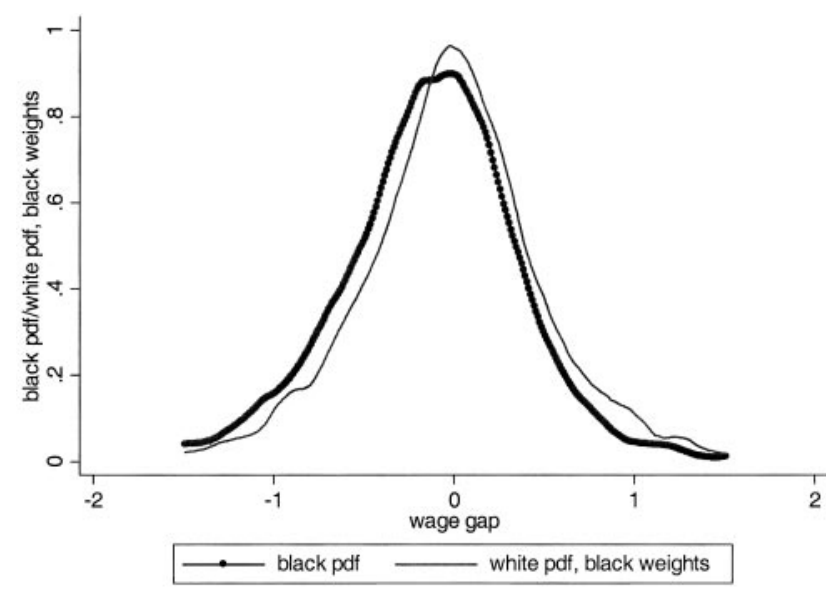

(A) Black men

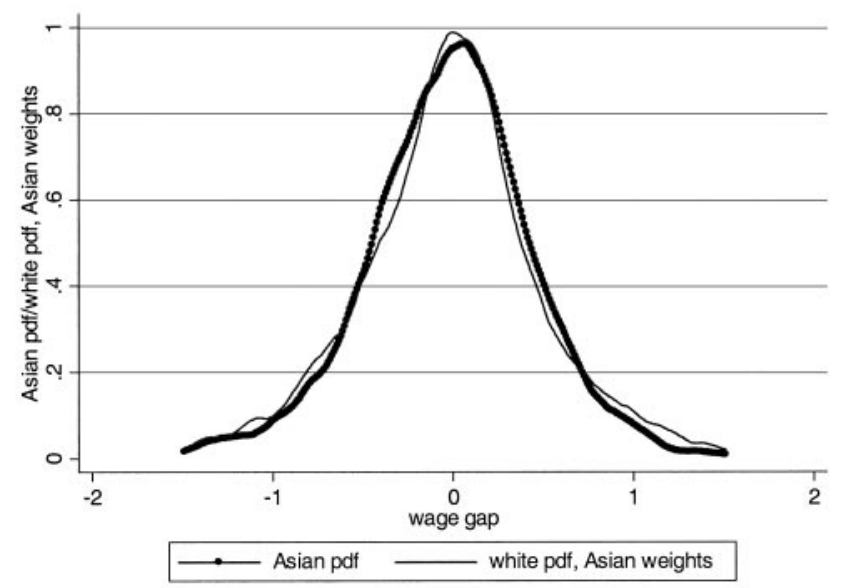

(C) Asian men

ticular, among college-educated men who speak English at home, our estimated wage gaps are very close to 0 for Hispanic and Asian men. Similarly, the unexplained wage gap is approximately 0 for black men with college-educated parents not born in the South. We provide fragmentary evidence that the unexplained gap for other black menSouthern-born men and those born elsewhere to poorly educated parents - is related to the generally poor quality of education afforded these men at the precollege and college levels.

A natural interpretation of our results is that in the U.S. market for college-educated men, rewards for productive skills are the same for minority men as for the majority. It is important, though, to repeat the caveat expressed above. We cannot rule out the possibility that the reduced wages associated with speaking a language other than English at home (for Hispanics and Asians) or with being born in the South (for blacks) are the consequence of cultural or class prejudice. Perhaps skin color or ethnicity per se is not the key factor in discriminatory practice, but rather prejudice aimed at minority men who are seen as "not fitting in" in the majority culture.

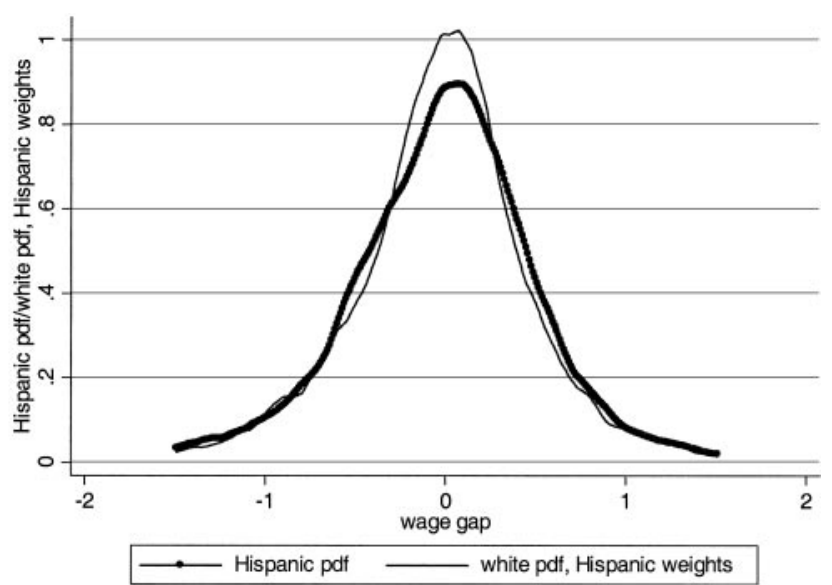

(B) Hispanic men
More generally, our research underscores a theme that is frequently expressed in the recent literature- that the key to reducing existing race and ethnicity wage disparities is the removal of obstacles that impede skill acquisition by minority children and youth. The literature has noted large race and ethnicity wage gaps among college-educated menevidence that has led some to conclude that improved educational opportunities for minorities cannot be the solution to reducing wage disparities. Our work suggests, to the contrary, that even among the most highly educated, minority wage gaps are in large measure the consequence of differential acquisition of productive skills. An important goal for research and policy is to identify and implement effective ways of reducing this disparity.

\section{REFERENCES}

Altonji, Joseph, and Rebecca Blank, "Gender and Race in the Labor Market," in Orley Ashenfelter and David Card (Eds.), Handbook of Labor Economics, Vol. 3 (New York: Elsevier Science Press, 1999).

Barsky, Robert, John Bound, Kerwin Charles, and Joe Lupton, "Accounting for the Black-White Wealth Gap: A Nonparametric Approach," 
Journal of the American Statistical Association 97 (2002), 663673.

Black, Dan, Seth Sanders, and Lowell Taylor, "Measurement of Higher Education in the Census and CPS," Journal of the American Statistical Association 98:463 (2003), 545-554.

Bollinger, Christopher, "Measurement Error in Human Capital and BlackWhite Wage Gap," this REVIEW, 85:3 (2003), 578-585.

Borjas, George J., "The Economics of Immigration," Journal of Economic Literature 32 (1994), 1667-1717.

Brown, Charles, "Black-White Earnings Ratios since the Civil Rights Act of 1964: The Importance of Labor Market Dropouts," Quarterly Journal of Economics 99 (1984), 31-44.

Brown, Charles, and Mary Corcoran, "Sex-Based Differences in School Content and the Male/Female Wage Gap," Journal of Labor Economics 15 (1997), 431-465.

Butler, Richard, and James J. Heckman, "The Government's Impact on the Labor Market Status of Black Americans: A Critical Review," in Farrell E. Bloch and Leonard J. Hausman (Eds.), Equal Rights and Industrial Relations (Madison, WI: Industrial Relations Research Association, 1977).

Canty, Angelo, and A. C. Davison, "Resampling-Based Variance Estimation for Labour Force Surveys," The Statistician 48:3 (1999), 379-391.

Card, David, and Alan B. Kruger, "School Quality and Black-White Relative Earnings: A Direct Assessment," Quarterly Journal of Economics 107 (1992a), 151-200.

"Does School Quality Matter? Return to Education and the Characteristics of Public Schools in the United States," Journal Political of Economy 100 (1992b), 1-40.

Daniel, Kermit, Dan Black, and Jeff Smith, "Does Affirmative Action Raise Wages? Racial Differences in the Effects of College Quality and Student Body Diversity on Wages," in Gary Orfield (Ed.), Diversity Challenged (Cambridge, MA: Harvard Education Publishing Group, 2001).

Duleep, Harriet, and Seth Sanders, "Discrimination at the Top: AmericanBorn Asian and White Men," Industrial Relations 31 (1992), 416-432.
Ehrenberg, Ronald, and Donna Rothstein, "Do Historically Black Institutions of Higher Education Confer Unique Advantages on Black Students: An Initial Analysis," NBER working paper no. 4356 (1993).

Haviland, A., "Understanding Wage Gaps among the Highly Educated," unpublished $\mathrm{PhD}$ dissertation, Carnegie Mellon University, Department of Statistics and Heinz School of Public Policy (2003).

Heckman, James J., Hidehiko Ichimura, and Petra Todd, "Matching As an Econometric Evaluation Estimator," Review of Economic Studies 65 (1998), 261-294.

Heckman, James J., Lance Lochner, and Petra Todd, "Fifty Years of Mincer Earnings Regressions," NBER working paper no. 9732 (2003).

Herrnstein, Richard, and Charles Murray, The Bell Curve: Intelligence and Class Structure in American Life (New York: Free Press, 1994).

Neal, Derek, and William Johnson, "The Role of Premarket Factors in Black-White Wage Differences," Journal of Political Economy 104 (1996), 869-895.

O'Neil, June, "The Role of Human Capital in Earnings Differences between Black and White Men," Journal of Economic Perspectives, 4 (1990), 25-45.

Racine, Jeffrey S., and Carole A. Green, "Nonparametric Estimation of Union and Gender Wage Gaps," unpublished paper, Syracuse University (2002).

Rodgers, William, and William Spriggs, "What Does the AFQT Really Measure? Race, Wages, Schooling and the AFQT Score," Review of Black Political Economy 24:4 (1996), 13-46.

Shao, Jun, and Dongsheng Tu, The Jackknife and Bootstrap (New York: Springer-Verlag, 1995).

Trejo, Stephen, "Why Do Mexican Americans Earn Low Wages?" Journal of Political Economy 105:6 (1997), 1235-1268.

Zeng, Zhen, and Yu Xie, "Asian-Americans' Earnings Disadvantage Reexamined: The Role of Place of Education," American Journal of Sociology 109:5 (2004), 1075-1108. 
Copyright of Review of Economics \& Statistics is the property of MIT Press and its content may not be copied or emailed to multiple sites or posted to a listserv without the copyright holder's express written permission. However, users may print, download, or email articles for individual use. 